\title{
PAYED: Programa de Actualización y Especialización en Documentación
}

\author{
José Antonio Merlo Vega; Carlos García-Figuerola Paniagua; \\ Araceli García Rodríguez
}

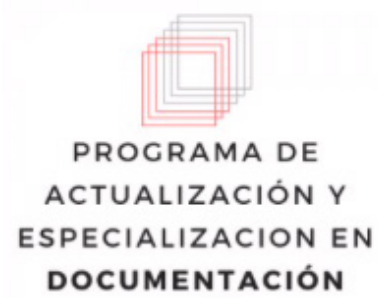

PAYED 2018/2019

$\Omega_{1}^{L}$

l Programa de Actualización y Especialización en Documentación surge tras un proyecto piloto puesto en marcha en el curso académico 2017-2018 por el Departamento de Biblioteconomía y Documentación de la Universidad de Salamanca.

Es un programa destinado a:

- Estudiantes del Grado en Información y Documentación y las dobles titulaciones correspondientes de la USAL.

- Estudiantes del Máster en Sistemas de Información Digital de la USAL.

- Egresados y egresadas de las diferentes titulaciones de la USAL relacionadas con la Documentación.

El objetivo del programa es actualizar y completar la formación de los estudiantes y titulados y adaptarla a lo requerido por la sociedad.

El plan formativo se compone de talleres y seminarios de corta duración que se complementan entre sí, pero que pueden seguirse de forma independiente.

Se entrega una constancia por cada uno de los cursos realizados, así como un certificado final que acredita el número de horas totales realizadas dentro del programa y los cursos que se han seguido. 
Las principales innovaciones del programa han sido:

- El establecimiento de sinergias entre los alumnos de las diferentes titulaciones que se imparten en la misma Facultad.

- Contribuir a mantener el contacto y el vínculo con la Universidad de los egresados.

- Mantener el compromiso de actualización profesional desde la propia Universidad.

- Promocionar los estudios de Máster entre los estudiantes de Grado al dar a conocer entre estos últimos los contenidos de las materias impartidas.

- Compartir y racionalizar los recursos económicos de Departamento, Máster y Facultad.

El programa se ha dado a conocer en diversos medios como el Blog del Departamento de Biblioteconomía y Documentación, cursos en Studium, el Foro de Estudiantes y Egresadas/ os de Documentación (FEED), las redes sociales de la Facultad y del Director del Departamento, así como en la prensa local.

La organización del programa corre a cargo del Departamento de Biblioteconomía y Documentación, del Máster en Sistemas de Información Digital y de la Facultad de Traducción y

En cuanto a la evaluación, en la segunda convocatoria del

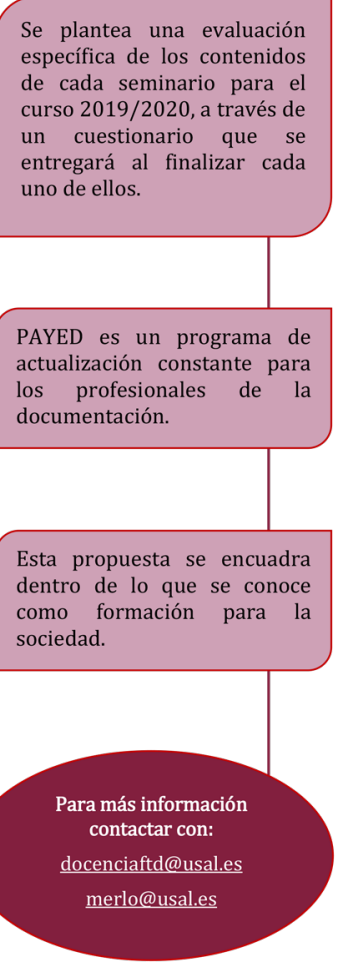
programa se ha realizado una evaluación general del número y tipo de participantes obteniendo los siguientes resultados:

- Número total de inscripciones en todos los cursos: 252.

- Número de alumnos: 110, de los cuales:

- 52 son estudiantes de Grado.

- 28 son titulados.

- 15 son estudiantes de Máster.

- 6 son profesores.

- 9 son otros profesionales o estudiantes de diferentes titulaciones.

Con este análisis de cada seminario se pretende incidir en la toma de decisiones de cara a la oferta del programa en el próximo curso. 